\title{
Características clínicas y epidemiológicas de pacientes ambulatorios en un centro de triaje COVID-19: una experiencia peruana
}

\section{Clinical and epidemiological characteristics of outpatients in a COVID-19 triage center: a Peruvian experience}

\author{
Anthony Ramos-Yataco ${ }^{1, a}$, Kelly Meza ${ }^{2, b}$, Silvana Loli-Guevara, ${ }^{3, c}$, Eddu Canales ${ }^{3, d}$ \\ 'Hospital Ricardo Cruzado Rivarola. Nazca, Perú. \\ ${ }^{2}$ Department of Pediatrics, Division of Pediatric Nephrology, Weill Cornell Medicine. New York, USA. \\ ${ }^{3}$ Sociedad Científica de San Fernando, Facutad de Medicina, Universidad Nacional Mayor de San Marcos. Lima, Perú. \\ ${ }^{a}$ Médico cirujano, ORCID: https://orcid.org/0000-0001-6224-3372 \\ ${ }^{\mathrm{b}}$ Médico cirujano, ORCID: https://orcid.org/0000-0002-1777-2360 \\ c Estudiante de medicina, ORCID: https://orcid.org/0000-0001-7586-5146 \\ ${ }^{d}$ Estudiante de medicina, ORCID: https://orcid.org/0000-0003-3536-6603
}

An Fac med. 2021;82(3):236-8. / DOI: https://doi.org/10.15381/anales.v82i3.21087

Correspondencia:

Silvana Loli-Guevara

silvana.Ioli@unmsm.edu.pe

Recibido: 22 de julio 2021

Aprobado: 27 de agosto 2021

Publicación en línea: 8 de septiembre 2021

Conflictos de interés: Los autores declaran no tener conflictos de interés.

Fuente de financiamiento: Autofinanciado

Contribuciones de autoría: ARY formó parte del personal de salud en contacto directo con los pacientes y participó en la concepción del estudio. KM, SLG, EC concibieron, diseñaron la investigación, recolectaron datos redactaron y aprobaron la versión final de la carta al editor. KM, SLG, EC desarrollaron la parte de análisis estadístico. Todos los autores aprobaron la versión final del manuscrito.

Citar como: Ramos-Yataco A, Meza K, Loli-Guevara S, Canales E. Características clínicas y epidemiológicas de pacientes ambulatorios en un centro de triaje COVID-19: una experiencia peruana. An Fac med. 2021;82(3):236-8. DOI: https://doi.org/10.15381/anales. v82i3.21087
Sr. Editor,

La pandemia por COVID-19 fue declarada en marzo del $2020^{(1)}$. En el Perú, en el mes julio del 2021 existían 2109294 casos confirmados ${ }^{(2)}$, con más diez mil casos y 364 fallecidos en la región de Nasca, Ica ${ }^{(3)}$.

Los centros de triaje han sido recomendados a nivel mundial, ya que contribuyen al diagnóstico y tratamiento temprano del COVID-19 (4). En Perú estos centros se implementaron como una medida para el control de los nuevos casos, además de encargarse de realizar seguimiento a los contactos positivos; así, constituye una estrategia fundamental en el control de la magnitud del brote de contagios ${ }^{(5)}$

En tal sentido, realizamos una investigación cuyo objetivo fue reportar las características demográficas, clínicas y prevalencia de la infección por SARS-CoV-2 mediante un estudio observacional analítico transversal en el centro de triaje del Hospital Ricardo Cruzado Rivarola (HRCR), ubicado en Nazca, Perú, entre los meses de abril a junio 2020. Las pruebas de reacción en cadena de la polimerasa con transcriptasa inversa (RT-PCR) de secreción nasofaríngea fueron procesadas en el Instituto Nacional de Salud y las pruebas serológicas fueron utilizadas para el diagnóstico de COVID-19 siguiendo el flujograma de atención del HRCR (Figura 1). Las variables consideradas fueron sexo, edad, antecedente de contacto para COVID-19, síntomas auto reportados, signos vitales y resultados de la prueba RT-PCR o serológica para SARS-CoV-2, características sociodemográficas, clínicas y comorbilidades. En el análisis se usó Chi-cuadrado o la prueba de Fisher. El estudio tuvo la aprobación del Comité de Ética de la Facultad de Medicina de la Universidad Nacional Mayor de San Marcos. Los datos de los participantes se codificaron con códigos guardando siempre en reserva la información, garantizando su confidencialidad.

La muestra incluyó un total de 272 pacientes; sin embargo, 64 registros fueron descartados por falta de información (variables clínicas y resultados de pruebas diagnósticas incompletas) y finalmente el análisis involucró 208 pacientes. Entre las variables sociodemográficas, hubo una mayor proporción de varones $(51,4 \%)$, la profesión más frecuente fue policía $(n=16)$, seguida de personal de salud ( $n=14)$. El $21,6 \%$ de pacientes fue menores de 18 años, con una media de edad de 9 (5-14) años. Los pacientes que reportaron haber tenido contacto con un paciente positivo representaron el 62,5\% del total $(n=130)$. Respecto a las variables clínicas, $108(51,9 \%)$ pacientes refirieron haber presentado algún síntoma relacionado con la infección de SARS-COV-2, con una media de tiempo de enfermedad de 4,8 días $\pm 3,8$. Los síntomas más frecuentes fueron cefalea, tos y odinofagia. La obesidad fue la comorbilidad más frecuente. Tabla 1.

Los pacientes positivos a SARS-COV-2 fueron 51 (24,5\%), con una mayor proporción de varones (52,9\%). La edad media fue 32,19 (16,5) años, 10 pacientes tenían 18 o menos años. El 86,3\% reportó haber tenido contacto con un paciente positivo. El diagnóstico se realizó en 39 de ellos con la prueba serológica y en 12 con la prueba RT-PCR En el análisis bivariado se encontró que las variables asociadas a tener un resultado positivo de COVID-19 fueron obesidad (OR 9,5; IC:3,43-26,45), fiebre (OR 4; IC:1,84-8,83), tos (OR 2,74; IC: 1,34-5,6), y contacto con paciente COVID-19 positivo (OR 5,1; IC: 2,20-12,23). Tabla 1. 


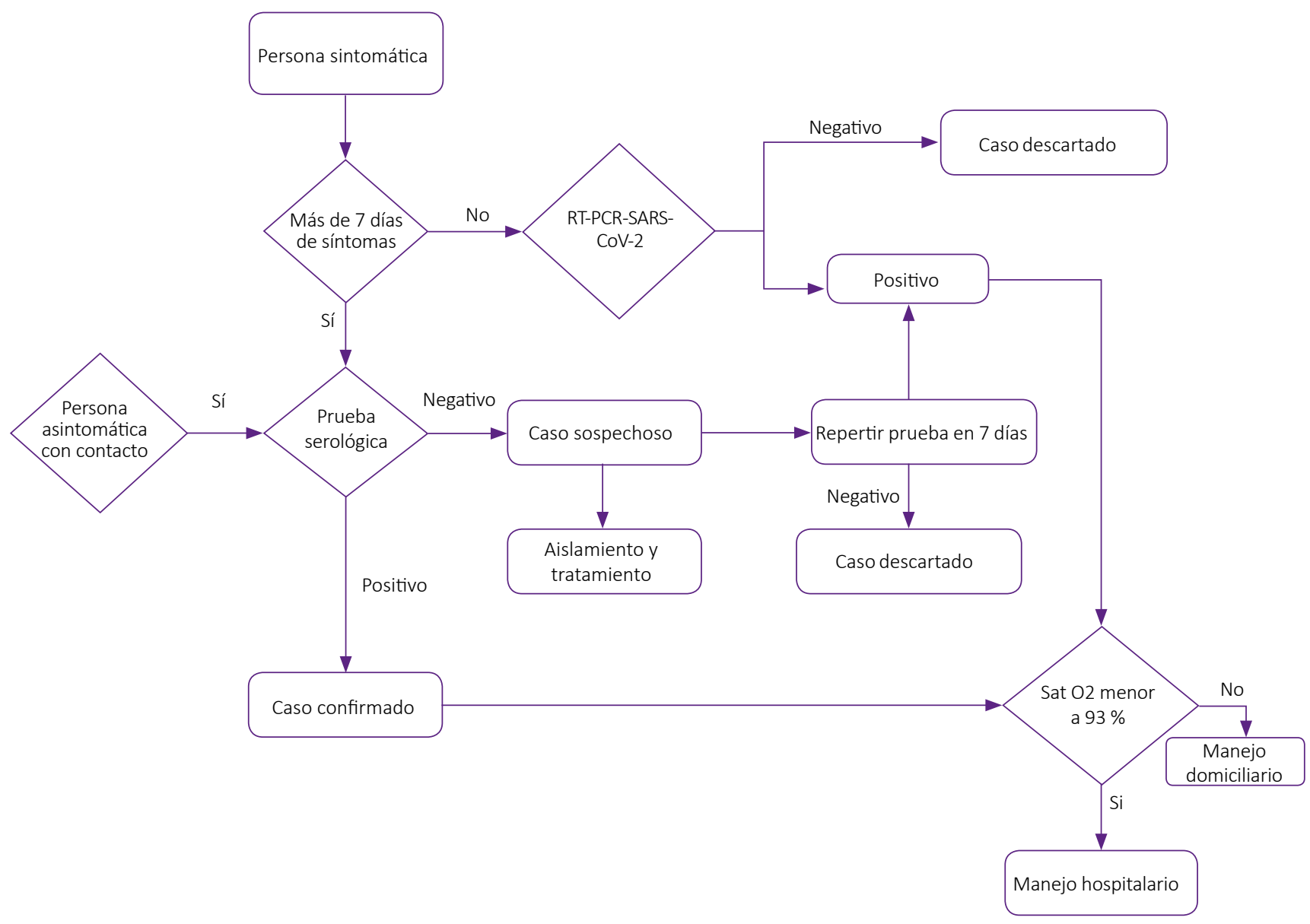

Figura 1. Flujograma de diagnóstico en el Centro de Triaje COVID-19 del Hospital Ricardo Cruzado Rivarola, Nazca, Perú. AbrilJunio, 2020.

RT-PCR: Reacción cadena polimerasa en tiempo real, Sat O2: saturación de oxígeno

En nuestro estudio encontramos que la media de tiempo desde el inicio de síntomas fue de 4,8 días al momento del triaje, conforme con lo reportado en la literatura, donde el tiempo promedio entre el inicio de síntomas y el primer contacto con un servicio de salud fue de 5 días ${ }^{(6)}$. Los pacientes asintomáticos con infección de SARS-CoV-2 constituyeron el $43,1 \%$, cifra mucho mayor a la encontrada por Peyrony en el triaje de un departamento de emergencias $(4,4 \%)^{(7)}$; la mayoría de ellos fueron contactos de pacientes positivos, debido al seguimiento de pacientes positivos ("contact tracing") realizado por este centro de triaje.

En nuestro estudio, los pacientes que reportaron haber tenido contacto con un paciente positivo, tuvieron mayor probabilidad (OR=5,1 Cl: 2,20-12,23) de ser positivos al realizarse la prueba diagnóstica. El cribado a familiares de pacientes con la infección es importante para el control de brote, y son estos quienes tienen mayor probabilidad de contagio, debido a la falta de medidas de control para el contacto dentro del hogar ${ }^{(8)}$. La obesidad se asoció a una mayor probabilidad de tener la infección por SARS-Cov-2 (OR=9,5 Cl: 3.43-26.45). La obesidad ha sido descrita como un factor de mal pronóstico para la infección con SARS-Cov-2; así, en el Perú, el $85 \%$ de los pacientes fallecidos por coronavirus eran obesos ${ }^{(9)}$.

En Perú, los contactos directos aún son tamizados con pruebas serológicas luego de 7 días del contacto ${ }^{(10)}$. Sin embargo, la literatura científica registra una transmisión del virus en etapas muy tempranas de la enfermedad, incluso antes del inicio de los síntomas (5 a 6 días), generando un tiempo ventana de propagación ${ }^{(5) "}$. Una solución para la detección precoz en estos pacientes sería el uso de RT-PCR, que permite un diagnóstico antes de los 6 días de enfermedad, implicando una menor probabilidad de propagación gracias al aislamiento temprano. Sin embargo, aunque estas pruebas tienen un alto rendimiento en este grupo de pacientes, en el Perú las pruebas RTPCR representan solo el $25 \%$ de todas las pruebas empleadas para el diagnóstico de COVID-19 ${ }^{(5)}$.

Nuestros hallazgos muestran que en pacientes que acuden a un centro de triaje de COVID-19, la fiebre, tos, obesidad y el antecedente de contacto con un caso, aumentaron la probabilidad de resultar positivo a la infección por SARSCoV-2. Es importante conocer el perfil de 
Tabla 1. Características de pacientes ambulatorios atendidos en el Centro de Triaje COVID-19 del Hospital Ricardo Cruzado Rivarola, Nazca, Perú. Abril - Junio, 2020.

\begin{tabular}{|c|c|c|c|c|}
\hline Características & $\begin{array}{l}\text { COVID-19 Negativo } \\
(n=157)\end{array}$ & $\begin{array}{l}\text { COVID-19 Positivo } \\
(n=51)\end{array}$ & $\begin{array}{c}\text { Total } \\
(n=208)\end{array}$ & p valor \\
\hline Edad y media (DE), años & $32,05 \pm 16,5$ & $32,19 \pm 16,5$ & $32,2 \pm 16,7$ & 0,962 \\
\hline Sexo, femenino & $83(77,6 \%)$ & $24(22,4 \%)$ & 107 & 0,471 \\
\hline \multicolumn{5}{|l|}{ Antecedente } \\
\hline Paciente con contacto COVID-19 & $86(54,8 \%)$ & $44(86,3 \%)$ & $130(62,5 \%)$ & $<0,001^{*}$ \\
\hline Obesidad & $6(3,8 \%)$ & $14(27,4 \%)$ & $20(9,6 \%)$ & $0,012 *$ \\
\hline IMC percentil en $\leq 18$-años & $52,6 \pm 40,2$ & $35,8 \pm 28,4$ & $39,5 \pm 30,7$ & 0,413 \\
\hline IMC en adultos & $29,2 \pm 4,9$ & $26,5 \pm 6,3$ & $27 \pm 1,7$ & 0,415 \\
\hline Tiempo de síntomas, (días) & $4,8 \pm 3,3$ & $4,8 \pm 4,3$ & $4,8 \pm 3,8$ & 0,982 \\
\hline \multicolumn{5}{|l|}{ Signos vitales al ingreso, mediana (IQR) } \\
\hline Frecuencia cardíaca & $87(80-95)$ & $89(87-94,75)$ & $89,3 \pm 16,5$ & 0,391 \\
\hline Frecuencia respiratoria & $23(18-25)$ & $24(21-25)$ & $24,3 \pm 9,3$ & 0,934 \\
\hline Saturación de oxígeno (\%) & $97(96-98)$ & $96(94-97)$ & $94,9 \pm 3,3$ & 0,261 \\
\hline Temperatura $\left({ }^{\circ} \mathrm{C}\right)$ & $36,7(36,5-36,8)$ & $36,7(36,8-36,5)$ & $37,2 \pm 3,7$ & 0,272 \\
\hline Presión arterial sistólica (mmHg) & $110(100-120)$ & $100(100-110)$ & $102,1 \pm 8,6$ & 0,094 \\
\hline Presión arterial diastólica $(\mathrm{mmHg}) *$ & $70(60-80)$ & $60(60-70)$ & $65 \pm 1,3$ & $0,012^{*}$ \\
\hline \multicolumn{5}{|l|}{ Síntomas (\%) } \\
\hline Fiebre & $16(10,2 \%)$ & $16(31,4 \%)$ & $32(15,5 \%)$ & $0,001^{*}$ \\
\hline Tos & $26(16,6 \%)$ & $18(35,3 \%)$ & $44(21,3 \%)$ & $0,005^{*}$ \\
\hline Diarrea & $7(4,5 \%)$ & $3(5,8 \%)$ & $10(4,8 \%)$ & 0,672 \\
\hline Fatiga & $4(2,5 \%)$ & $3(5,8 \%)$ & $7(3,3 \%)$ & 0,263 \\
\hline Mialgia & $25(15,9 \%)$ & $10(19,6 \%)$ & $35(16,8 \%)$ & 0,504 \\
\hline Disnea & $2(1,2 \%)$ & $2(3,9 \%)$ & $4(1,9 \%)$ & 0,231 \\
\hline Dolor torácico & $8(5,1 \%)$ & $1(1,9 \%)$ & $9(4,4 \%)$ & 0,332 \\
\hline Cefalea & $34(21,6 \%)$ & $10(17,6 \%)$ & $44(20,7 \%)$ & 0,531 \\
\hline Dolor de garganta & $32(20,4 \%)$ & $9(17,6 \%)$ & $41(19,7 \%)$ & 0,652 \\
\hline Asintomático & 78 (49\%) & $22(43,1 \%)$ & $100(48,1 \%)$ & 0,414 \\
\hline
\end{tabular}

IMC: Índice de masa corporal, * p-valor $<0,05$

los usuarios de los centros de triaje para COVID-19, por ser pilares para el diagnóstico y aislamiento temprano que son fundamentales para reducir el impacto de la pandemia en el Perú

\section{REFERENCIAS BIBLIOGRÁFICAS}

1. Cucinotta D, Vanelli M. WHO Declares COVID -19 a Pandemic. Acta Biomed. 2020;91(1):157-60.

2. Coronavirus en el Perú : casos confirmados [Internet] [citado el 22 de Agosto 2021]. Disponible en: https://muw . gob.pe/8662-coronavirus-en-el-peru-casos-confirmados

3. Ministerio de Salud del Perú [Internet]. Datos Abiertos MINSA y Gestión del Conocimiento en Covid -19. [citado el 22 de Agosto 2021]. Disponible en: https://www.minsa.gob.pe/datosabiertos/

4. Ayebare RR, Flick R, Okware S, Bodo B, Lamorde M. Adoption of COVID -19 triage strategies for low-income settings. Lancet Respir Med [Internet]. 2020 [citado el 5 de Septiembre 2020];8(4):e22. Disponible en: https://www.thelancet.com/journals/ lanres/article/PIIS2213-2600(20)30114-4/abstract

5. Hao-Yuan C, Shu-Wan J, Ding-Ping L, Ta-Chou Ng, Wan-Ting $\mathrm{H}$, Hsien-Ho L, et al. Contact Tracing Assessment of COVID -19 Transmission Dynamics in Taiwan and Risk at Different Exposure Periods Before and After Symptom Onset. JAMA Intern Med. 2020;180(9):1156-1163. DOI: 10.1001/jamainternmed.2020.2020

6. Khalili M, Karamouzian M, Nasiri N, Javadi S, Mirzazadeh A, Sharifi H. Epidemiological characteristics of COVID -19: a systematic review and meta-analysis. Epidemiol Infect. 2020;148:e130.

7. Peyrony O, Marbeuf-Gueye C, Truong V, Giroud M, Rivière C, Khenissi K, et al. Accuracy of Emergency Department Clinical Findings for Diagnosis of Coronavirus Disease 2019. Ann Emerg Med. 2020;76(4): 405-412. DOI: 10.1016/j.annemergmed.2020.05.022
8. Liu Z, Wu Q, Zou Z, Yao Y, Cai J, Liu T, et al. Investigation of a family cluster outbreak of COVID -19 indicates the necessity of CT screening for asymptomatic family members in close contact with confirmed patients. J Thorac Dis. 2020;12(7):3673-81.

9. Plataforma digital única del Estado Peruano [Internet]. El $85.5 \%$ de pacientes fallecidos con comorbilidades por Covid-19 padecian obesidad. [citado el 11 de Septiembre 2020]. Disponible en: https://www.gob.pe/qu/institucion/minsa/ noticias/286005-el-85-5-de-pacientes-fallecidoscon-comorbilidades-por-covid-19-padecian-obesidad

10. Plataforma digital única del Estado Peruano [Internet]. Resolución Ministerial N¹93-2020- MINSA. [citado el 31 de Agosto de 2020]. Disponible en: https://www.gob.pe/institucion/minsa/normaslegales/473575-193-2020-minsa 